\title{
Imagineering Learning With Logical Problem Solving
}

\author{
Pongsakorn Kanoknitanunt ${ }^{1}$, Prachyanun Nilsook ${ }^{1} \&$ Panita Wannapiroon $^{1}$ \\ ${ }^{1}$ King Mongkut's University of Technology North Bangkok, Thailand \\ Correspondence: Pongsakorn Kanoknitanunt, King Mongkut's University of Technology North Bangkok, \\ Bangkok, Thailand. E-mail: pongsakorn.kan@kmutnb.ac.th
}

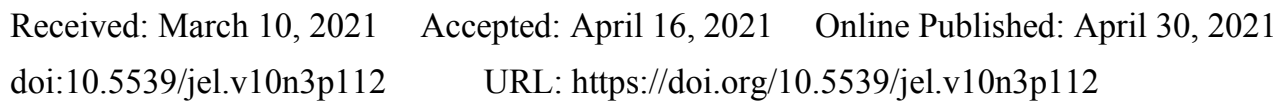

\begin{abstract}
This study aimed at developing an imagineering learning process model with logical solutions by using documentary research and relevant experts' viewpoints with regard to the process of Imagineering Learning - problem-based learning (PBL) involving logical and computational thinking. The data were then synthesized in order to find the relationship of learning theory to achieve an Imagineering Learning process by solving logic problems. The analysis of related documents and research revealed that the Imagineering Learning process involving logical problem solving consisted of 6 important steps as follows: 1) the problem-solving stage, 2) the problem-solving design stage, 3) the innovation development stage, 4) the innovation presentation, 5) the innovation improvement stage, 6) the evaluation stage. The aforementioned learning process can also result in the development of students' innovative skills, and encouraging learners to develop such skills. The emphasis in terms of the Imagineering process is to create inspiration for the imagination of things that do not yet occur. The process then continues with innovation development by using the PBL process in which students learn solution thinking, focusing on logically-prioritizing problems and their causes and effects. This creates structural and systematic learning through practice, so that students can develop the ability to seek knowledge and develop problem-solving abilities.
\end{abstract}

Keywords: imagineering, problem-based learning, logical thinking, computational thinking, learning process

\section{Introduction}

The improvement and the diversity of teaching and learning methods are mandatory for the education system during the digital era in the modern word. Innovators are highly encouraged, especially in industrialized countries, such as the United States. According to President Barack Obama, computer science is accessible for students at all levels to prepare and empower them as potential creators in the technology-driven world (Obama, 2016). Likewise, high-skilled and experienced personnel are essential during the age of science and technology in order to achieve Thailand 4.0 Model. The required skills according to Thailand 4.0 Model consist of 1) Core subject and 21 st Century Themes, 2) learning and innovation skills, 3) information media and technology skills, and 4) life and career skills. In addition, computer skill is one of the most important experiential learning that can be applied in problem-solving and for further innovations in the future (Development of characteristics in the new generation of learners to respond to the educational reformation in the 2nd decade by integrating IT in the project-based instructional management, 2012). Imagineering Learning is a newly-developed learning concept that facilitates the development of required skills in learners during the 21 st century. This concept allows learners to reach their goals by encouraging self-learning, creativity, critical thinking and innovation skills. Imagineering learning can be achieved through both classroom learning and self-learning from problem-solving and project work (Nilsook \& Panita Wannapiroon, 2013; Mario Riojas \& Susan Lysecky, 2012). Problem-based learning is a strategy that promotes active learning and encourages learners to seek solutions based on the problems (Balim et al., 2016). Thus, learners will accomplish their learning objectives by solving the problems (McLoone et al., 2016). Although problem-based learning promotes self-learning environment, classroom learning is still maintained. It is also an effective tool for learners with distinct abilities and skills, as learners are able to choose problems and learning methods based on their interests (Greenwald, 2000). The characteristic of this approach is to engage students with problems that they may encounter in their everyday life as the starting point of the learning process. This will stimulate the development of cause-and-effect problem-solving skills by focusing on how they make a decision based on their knowledge, and learn to collaborate with their peers. This will result in the development of new knowledge that is based on existing knowledge. It will also create 
interaction between learners, each with different skills, as they work together to find solutions. Another advantage of cooperative learning is that the learners will improve their communication skills (Barkley et al., 2004). This approach is a student-centered teaching method that provides direct experience through pleasant and challenging activities. It promotes problem-solving skills through seeking for knowledge and learning by experimenting, until the learners can discover the required solutions. This results in a direct learning experience for learners and develops their ability to integrate knowledge into the problem-solving process (Suebnukarn \& Haddawy, 2004). Computational thinking is the ability to solve problems, analyze, and design or develop systems. This ability is based on conceptual calculations and sequential thinking processes which can be applied in daily life. This concept reveals the capabilities and limitations of processing, involving humans and machines. Due to the rise of complex and substantial information, the collaboration between humans and machines is needed for problem solving. Systems will be developed by men so that machines can perform and work efficiently. This idea is the basis of technological design and development aimed to solve problems or fulfil human needs (Denning, 2009). This technological learning is the learning of science that is not restricted to the operational level, but involves an integration of sequential computations, logical thinking, and creating concrete objects from an individual's imagination (Ruthmann et al., 2010). It enables the extension of knowledge from the old to the new, and the combination of knowledge from a wide range of subjects to come up with a new body of knowledge (Bower et al., 2017). The most effective learning allows learners to learn by doing actions incorporating careful design and processes to create systematic learning. Problem-based learning is a learning method that allows students to study, research and practice independently, according to their abilities, aptitudes, and interests based on a scientific or any other process used in the study, to find answers on a subject of interest, supported by close advice and consultation with teachers. Logical problem-solving skills are based on rational thinking that uses the principles of cause and effect in systematically solving problems, to allow learners to distinguish things clearly and logically. From the above principles and concepts, researchers realize the importance of developing the Imagineering Learning process by using logical problem solving as a guideline for developing a teaching and learning process that promotes the ability to systematically-create innovation.

\section{Method}

Imagineering is a graduate education management model that focuses on encouraging learners to be a Social Change Agent with the basic competencies of scientists, engineers, and creative thinkers. This may be referred to as Imagineering. It is not a specific occupation, but will serve to generate demand or solve new problems with the support of unprecedented imagination made tangible, work approaches, operations or new ways of life for the benefit of the society in which the imaginer is involved (King Mongkut's University of Technology Thonburi, 2010). Imagineering is a process of learning which can be achieved through dreaming and doing (Disney, 1996). It involves making imagination become a reality that does not currently exist (Guzdial \& Tew, 2006). The process enables learners to recognize certain aspects of value, and then put it to use in daily life of the individual or of the group (Jarvis \& Howard Esbin, 2010). Imagineering emphasizes the value of emerging paradigms in a changing world. It aims to investigate the important factors in the surrounding reality of an organization from a descriptive viewpoint and appreciate the value of the artifacts of speech and mind. It was created through a process aimed at promoting and inspiring all those who might have imaginative initiatives, so that the organization can be opened to new possibilities for the future (Qiyue, 2013). Imagineering Learning is a new teaching management concept that is consistent with the development of learner characteristics in the 21st Century. It emphasizes the learner's ability to learn by themselves, be creative, and be able to innovate. As the goal of this approach is having a finished product, it encourages learners to start the thinking process and then work through it until the product which is the product of their imagination, exists. This process of learning can be taught both directly or through independent study, with the use of problem-solving and project work. These methods are particularly effective in engineering teaching. Learning with maximum efficiency will allow learners to learn by doing as part of a well-designed and systematic process which will result in systematic learning (Mario Riojas \& Susan Lysecky, 2012). 
Table 1. Synthesis of the Imagineering learning process

\begin{tabular}{|c|c|c|c|c|c|c|c|c|c|c|}
\hline Imagineering Learning & 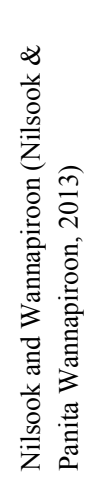 & 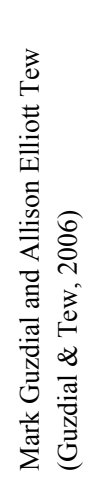 & 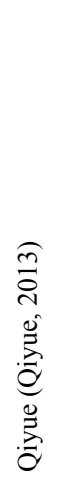 & 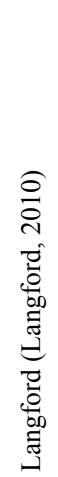 & 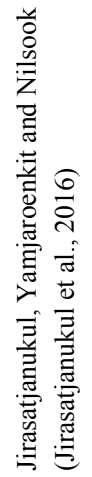 & 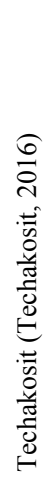 & 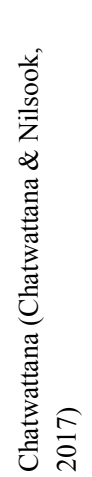 & 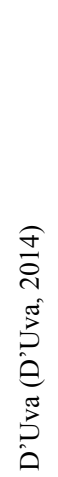 & 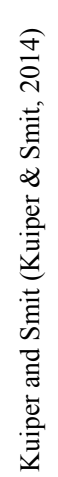 & $\begin{array}{l}\text { Synthesis } \\
\text { Results }\end{array}$ \\
\hline Imagine Stage & $\checkmark$ & $\checkmark$ & $\checkmark$ & $\checkmark$ & $\checkmark$ & $\checkmark$ & $\checkmark$ & & $\checkmark$ & $\checkmark$ \\
\hline Design State & $\checkmark$ & $\checkmark$ & $\checkmark$ & $\checkmark$ & $\checkmark$ & $\checkmark$ & $\checkmark$ & $\checkmark$ & $\checkmark$ & $\checkmark$ \\
\hline Development Stage & $\checkmark$ & $\checkmark$ & $\checkmark$ & & $\checkmark$ & & $\checkmark$ & $\checkmark$ & $\checkmark$ & $\checkmark$ \\
\hline Presentation Stage & $\checkmark$ & $\checkmark$ & $\checkmark$ & $\checkmark$ & $\checkmark$ & $\checkmark$ & $\checkmark$ & $\checkmark$ & & $\checkmark$ \\
\hline Improvement Stage & $\checkmark$ & $\checkmark$ & $\checkmark$ & & $\checkmark$ & $\checkmark$ & & & $\checkmark$ & $\checkmark$ \\
\hline Evaluation Stage & $\checkmark$ & $\checkmark$ & $\checkmark$ & $\checkmark$ & $\checkmark$ & $\checkmark$ & & & $\checkmark$ & $\checkmark$ \\
\hline
\end{tabular}

From Table 1, it can be seen that the Imagineering learning process consists of 6 steps: $1^{\text {st }}$ Imagine, $2^{\text {nd }}$ Design, $3^{\text {rd }}$ Develop, $4^{\text {th }}$ Present, $5^{\text {th }}$ Improve, $6^{\text {th }}$ Evaluate.

\section{Problem-Solving Learning}

PBL developed from the idea of an American educator, John Dewey, who discovered a method for teaching problem-solving by suggested that students should present problems that arise in real life, and help each other to find answers by themselves as a result of discovering information. This led to various teaching concepts that have now become popular. The concept of PBL itself is based on John Dewey's idea. PBL is a learner-centered approach that emphasizes problem-solving, and practicing solving problems, both cooperatively and individually (Howard \& Robyn, 1980; Spencer \& Jordan, 1999; Choden \& Kijkuakul, 2020). PBL allows students to learn by themselves and, at the same time, maintains a classroom-learning style. It is effective for learners of different abilities because students can choose problems and learning methods based on their particular development and interests (Greenwald, 2000). In conclusion, PBL is a teaching approach that can be used to develop students' problem-solving skills and encourage self-learning. In addition, PBL management is a deep approach that allows learners to understand and remember what they have learned in the long term, resulting in real learning. Cooperative learning and learning to work in response to a particular situation encourages learners to practice by themselves which leads to the development of problem-solving skills, and eventually for the learner to be able to study on his/her own and also work well in a group.

Table 2. Synthesis of PBL processes

\begin{tabular}{|c|c|c|c|c|c|c|c|c|c|}
\hline Problem-Based Learning & 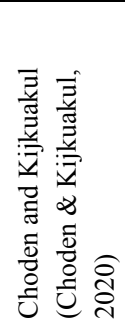 & 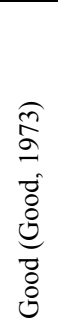 & 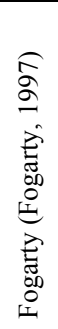 & 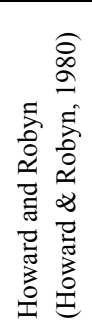 & 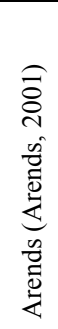 & 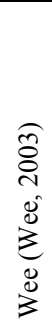 & 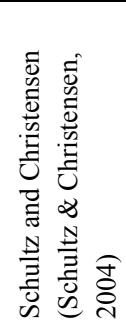 & 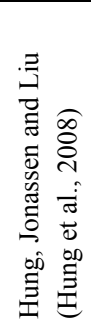 & $\begin{array}{l}\text { Synthesis } \\
\text { Results }\end{array}$ \\
\hline Clarify the Setting & $\checkmark$ & $\checkmark$ & & $\checkmark$ & & $\checkmark$ & $\checkmark$ & $\checkmark$ & $\checkmark$ \\
\hline Define the Problem & $\checkmark$ & $\checkmark$ & $\checkmark$ & & $\checkmark$ & $\checkmark$ & $\checkmark$ & $\checkmark$ & $\checkmark$ \\
\hline Analyses/Investigate the Case & $\checkmark$ & $\checkmark$ & $\checkmark$ & $\checkmark$ & & $\checkmark$ & $\checkmark$ & $\checkmark$ & $\checkmark$ \\
\hline Re-Structure the Problem & & $\checkmark$ & $\checkmark$ & $\checkmark$ & $\checkmark$ & $\checkmark$ & $\checkmark$ & $\checkmark$ & $\checkmark$ \\
\hline Formulate Learning Goals & $\checkmark$ & $\checkmark$ & & $\checkmark$ & $\checkmark$ & $\checkmark$ & $\checkmark$ & $\checkmark$ & $\checkmark$ \\
\hline Individual Learning & $\checkmark$ & $\checkmark$ & & $\checkmark$ & & $\checkmark$ & $\checkmark$ & $\checkmark$ & $\checkmark$ \\
\hline Report back to the Group & $\checkmark$ & $\checkmark$ & $\checkmark$ & $\checkmark$ & $\checkmark$ & $\checkmark$ & $\checkmark$ & $\checkmark$ & $\checkmark$ \\
\hline
\end{tabular}


From Table 2, it can be seen that the PBL process consists of 7 steps: Clarify the Setting, Define the Problem, Analyse/Investigate the Case, Re-structure the Problem, Formulate Learning Goals, Individual Learning, and Report back to the Group.

\section{Logical Thinking}

Logical thinking is critical thinking. It is rational thinking that solves a problem by considering various situations or pieces of information (Gagné \& Briggs, 1974). Logical thinking is the study of the principles of the correct use of cause and effect. This is the process of rationalizing what is expressed through words. The function of reasoning occurs on the left side of the brain involving the continuous process of transmitting structured data to visualize the speech is related to each other, until understanding occurs and more complex memories develop (Herrick, 1999). Rational thinking refers to the process of considering what is happening in the mind, or it is thinking that uses truth or principles. Even though two people may think about the same thing, their answers might not be the same (Solso, 1998). Logical thinking is a skill that requires the ability to understand the structure of a problem, and arrive at reasonable action. This will enable students to solve problems through a variety of thought processes, to achieve important outcomes or rules. Furthermore, learning to programming must rely on the problem-solving process, which requires reasonable or logical thinking (Kawamoto \& Arai, 2008). In conclusion, logical thinking is a matter of thinking systematically and with processes. In this regard, systematic thinking will allow learners to understand and prioritize ideas, encourage them to learn from different contexts, and to solve problems logically. If we can see and understand the nature of the problem and be ready to solve it, we can solve that problem by using our existing experience or knowledge. This idea works the same for solving a physics problem. If we can see and understand the nature of the problem along with having skills from existing knowledge to use as part of the problem-solving process, we will be able to apply strategies to solve the problem. The learner's efficiency in terms of solving problems will depend on the knowledge applied. To come up with correct problem-solving strategies involving a systematic method will help to make solving problems much easier (Heller \& Heller, 2000).

Table 3. Synthesis of the logical problem-solving process

\begin{tabular}{|c|c|c|c|c|c|c|c|}
\hline Logical Thinking Process & 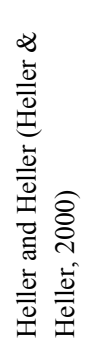 & 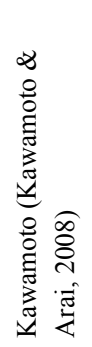 & 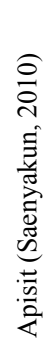 & 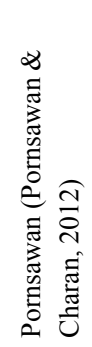 & 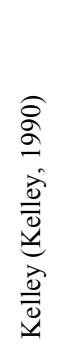 & 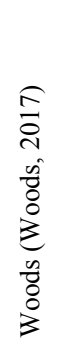 & Synthesis Results \\
\hline Focus the Problem & $\checkmark$ & & $\checkmark$ & & $\checkmark$ & $\checkmark$ & $\checkmark$ \\
\hline Describe the Physics & $\checkmark$ & $\checkmark$ & & $\checkmark$ & $\checkmark$ & & $\checkmark$ \\
\hline Plan the Solution & $\checkmark$ & $\checkmark$ & $\checkmark$ & & $\checkmark$ & $\checkmark$ & $\checkmark$ \\
\hline Execute the Plan & $\checkmark$ & $\checkmark$ & $\checkmark$ & $\checkmark$ & $\checkmark$ & $\checkmark$ & $\checkmark$ \\
\hline Evaluate the Answer & $\checkmark$ & & $\checkmark$ & $\checkmark$ & $\checkmark$ & $\checkmark$ & $\checkmark$ \\
\hline
\end{tabular}

From Table 3, we can see that the logical problem-solving process consists of 5 steps: 1. Focus on the Problem, 2. Describe the Physics, 3. Plan the Solution, 4. Execute the Plan, 5. Evaluate the Answer.

\section{Computational Thinking}

Computational thinking is a thinking process that involves determining problems and solutions that can be implemented efficiently with the use of data processing. Computational thinking incorporates critical thinking and problem-solving skills that involve solving problems in a calculated way. It doesn't mean thinking like a computer as thinking in this way shows the mechanisms of thought, while computational thinking is a collaborative and potentially creative approach to change and to solving a problem (Wing, 2006). It is also a process that requires problem solving skills and techniques. For example, software developers or software engineers have used it in programming. Its essence is to solve a problem step-by-step as other professions do to solve abstract problems such as those facing restaurant owners who don't want to have over-long queues, or an accountant finding ways to use new tools to record balances instead of writing the details down on paper (Poolsawas \& Dokprakhon, 2016). Computational thinking provides solutions to problems in system design and 
in understanding of human behavior. It takes the basic concepts of computer science that are fundamental to all, not only to computer scientists (Angevine, 2017; Threekunprapa \& Yasri, 2020). This skill is needed for workers in the 21 st Century. It is a skill that should be taught in all schools. Most people think of computational thinking as being found only in the computer science class. However, computational thinking is a basic skill for all humans, not just computer scientists. Teaching about thinking should be a process used in all educational institutions. Computational thinking is more than just programming, and cannot be learned directly. It must be indirectly instructed through different topics in terms of experience or activities (Lamprou \& Repenning, 2018). It is a basic idea and skill that everyone can learn and use in everyday life. Computational thinking is not used to create only computer engineers. Rather, it is a core competence that everyone should have. Computational thinking can be learned from childhood (Cho \& Lee, 2017) to solve problems and can be used to extend knowledge to other subjects (Lockwood \& Mooney, 2017). It is a skill that involves thinking processes and methods to solve complex problems using concepts from computer science. Computational thinking involves elements such as problem determination, compilation, analysis, and evaluation of possible solutions (Ching et al., 2018). It can be concluded that computational thinking is a thinking process skill that critically uses reasoning to solve problems. It is a sequence of steps that everyone can learn and use in their daily lives. It consists of systematic learning to solve problems through the evaluation of situations or activities, and being able to use technology to help develop such skills.

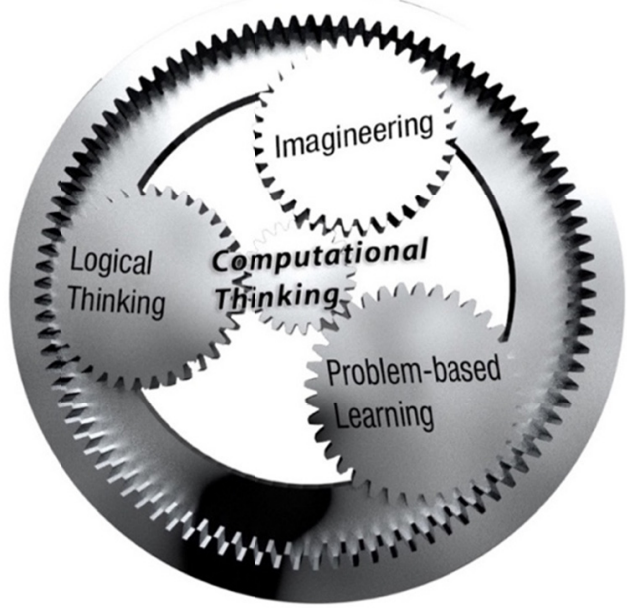

Figure 1. An Imagineering Learning process involving logical problem solving

\section{Research Methods}

This research aims to study imagineering processes in solving logical problems by using documentary research processes and the opinions of relevant experts in order to obtain synthetic results according from synthetic Tables 1,2 , and 3 . 
Table 4. Synthesize the Imagineering Learning process by solving logical problems.

\begin{tabular}{|c|c|c|c|c|c|c|c|c|}
\hline \multirow[t]{2}{*}{$\begin{array}{l}\text { Imagineering Learning with Logical } \\
\text { Problem Solvings }\end{array}$} & \multicolumn{3}{|c|}{ Imagineering } & \multicolumn{2}{|c|}{$\begin{array}{l}\text { Problem-based } \\
\text { Learning }\end{array}$} & \multicolumn{3}{|c|}{ Logical Thinking } \\
\hline & 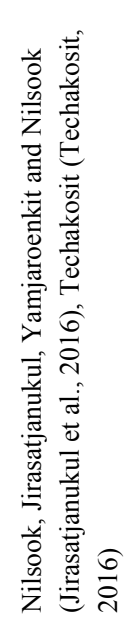 & 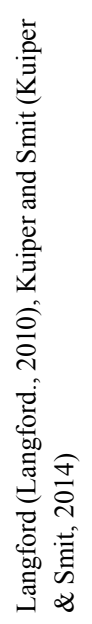 & 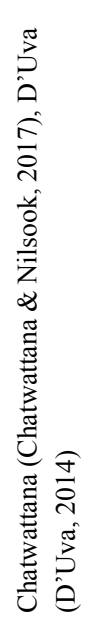 & 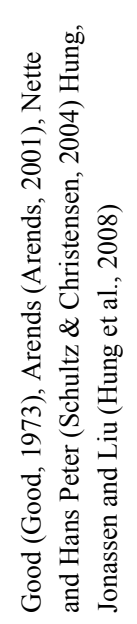 & 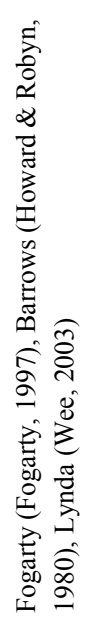 & 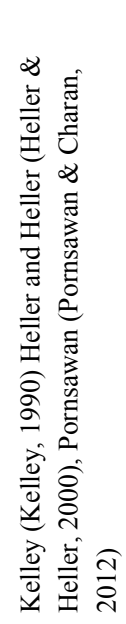 & 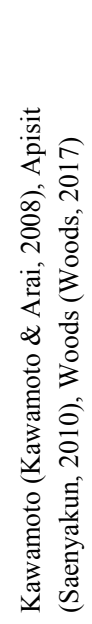 & $\begin{array}{l}\text { Synthesis } \\
\text { Results }\end{array}$ \\
\hline \multicolumn{9}{|l|}{ 1. Imagine Stage } \\
\hline 1.1 Clarify the Setting & $\checkmark$ & $\checkmark$ & $\checkmark$ & $\checkmark$ & $\checkmark$ & & & $\checkmark$ \\
\hline 1.2 Define and Investigate the Problem & $\checkmark$ & $\checkmark$ & $\checkmark$ & $\checkmark$ & $\checkmark$ & $\checkmark$ & $\checkmark$ & $\checkmark$ \\
\hline 1.3 Problem Analysis Correlation & $\checkmark$ & $\checkmark$ & $\checkmark$ & $\checkmark$ & $\checkmark$ & $\checkmark$ & $\checkmark$ & $\checkmark$ \\
\hline \multicolumn{9}{|l|}{ 2. Design Stage } \\
\hline 2.1 Re-Structure the Problem & $\checkmark$ & $\checkmark$ & $\checkmark$ & $\checkmark$ & $\checkmark$ & $\checkmark$ & $\checkmark$ & $\checkmark$ \\
\hline 2.2 Formulate Goals & $\checkmark$ & $\checkmark$ & $\checkmark$ & $\checkmark$ & $\checkmark$ & $\checkmark$ & $\checkmark$ & $\checkmark$ \\
\hline 2.3 Plan the Solution & $\checkmark$ & $\checkmark$ & $\checkmark$ & & & $\checkmark$ & $\checkmark$ & $\checkmark$ \\
\hline \multicolumn{9}{|l|}{ 3. Development Stage } \\
\hline 3.1 Individual Learning & $\checkmark$ & $\checkmark$ & $\checkmark$ & $\checkmark$ & $\checkmark$ & $\checkmark$ & $\checkmark$ & $\checkmark$ \\
\hline 3.2 Execute the Plan & $\checkmark$ & $\checkmark$ & $\checkmark$ & $\checkmark$ & $\checkmark$ & $\checkmark$ & $\checkmark$ & $\checkmark$ \\
\hline \multicolumn{9}{|l|}{ 4. Presentation Stage } \\
\hline 4.1 Presentation & $\checkmark$ & $\checkmark$ & $\checkmark$ & $\checkmark$ & $\checkmark$ & $\checkmark$ & & $\checkmark$ \\
\hline \multicolumn{9}{|l|}{ 5. Improvement Stage } \\
\hline 5.1 Evaluate the Answer & $\checkmark$ & $\checkmark$ & $\checkmark$ & & $\checkmark$ & $\checkmark$ & $\checkmark$ & $\checkmark$ \\
\hline \multicolumn{9}{|l|}{ 6. Evaluation Stage } \\
\hline 6.1 Solutions Report & $\checkmark$ & $\checkmark$ & & $\checkmark$ & $\checkmark$ & & & $\checkmark$ \\
\hline 6.2 Conclusion & $\checkmark$ & $\checkmark$ & & $\checkmark$ & $\checkmark$ & $\checkmark$ & $\checkmark$ & $\checkmark$ \\
\hline
\end{tabular}

From Table 4, it can be seen that the Imagineering Learning process by solving logic problems consisted of 6 important steps: $1^{\text {st }}$ Imagine, $2^{\text {nd }}$ Design, $3^{\text {rd }}$ Develop, $4^{\text {th }}$ Present, $5^{\text {th }}$ Improve and $6^{\text {th }}$ Evaluate.

\section{Results of the Research}

The research results from the synthesis of Tables 1, 2, 3, and 4 show that the Imagineering Learning process involving the process of solving logical problems consists of the following 6 steps:

Imagining the problem is the stage of determining the problem from one's imagination to find solutions to the problem. In this study the learners were divided into groups to determine the problem. They were then observed during a discussion involving the sharing of opinion with other members of the group. The aim was to analyze the relationship of the original information available to each person to create a feasibility analysis and to use in planning the solution.

The solution design stage is a step to bring together the opinions obtained from the imagining stage and to prioritize their importance. This could be done with a storyboard or scripting to use as a guideline for setting a learning goal and for obtaining more information. Then a prototype or solution guideline was prepared. The instructor can organize this stage as an activity for the students to make decisions comparatively by focusing on their own discussion and listening to others members' opinions.

Innovation development is the process of creating and testing the innovation. Learners operate according to a plan to create a prototype. This is a group activity that focuses on providing learners with the skills needed for a step-by-step performance in which the students help each other to do their work. The task can be divided into 
duties based on aptitude or individual interests in order to achieve the work needed to solve the problem as planned.

The Innovation Presentation Stage is the stage of presenting the work obtained from the innovation development stage. The instructor organized a presentation activity for learners to share their innovative approaches to solving imaginary problems. The presentation provides learners with an opportunity to interact with other groups. It is an activity that focuses on presenting empirical evidence of their work. The students must have good communication and presentation skills, and must have an open-mind when it comes to listening to others' opinions, including various suggestions from the other student groups.

At the stage of Innovation Improvement, suggestions received from experts are used to improve the work to make it more appropriate. The instructor organizes an activity for the students to help each other and to exchange knowledge between different groups of learners, all of which can be used for the improvement of the innovative model.

The Evaluation Stage is the evaluation of the work that has been created from the learners' imagination. This stage includes the evaluation of the quality of the work done in terms of whether or not it has met the target, and the objectives that are defined in the solution design stage. The instructor organizes an activity for each group to assess the students' performance. Students will consider their own work and that of other groups in terms of it being of a satisfactory quality or not, including allowing group members to make suggestions for the benefit of the development the next time.

\section{Discussion}

From the results of the research, it can be seen that Imagineering is a process of manipulating ideas and inspiration to take the initiative from the imagination, to produce an outcomes that does not yet exist, turning it into a reality by doing or inventing. The process of Imagineering consists of 6 steps: imagination, design, development, presentation, improvement and evaluation. The teaching approach that can be used to encourage problem-solving skills is the problem-based learning approach. This technique is aimed at creating understanding and solving problems. The problem itself is the starting point of the learning process which acts as a stimulus to encourage learners to take action on their own. It makes students develop problem-solving skills, encourages them to study on their own, and also to work well as a group member. This approach consists of 7 steps: 1) Clarify the Setting, 2) Define the Problem, 3) Analyze/Investigate the Case, 4) Re-Structure the Problem, 5) Set Learning Goals, 6) Engage in Individual Learning, 7) Report Back to the Group. Logical problem solving is a matter of systematic thinking and processes. With systematic thinking, we can understand and prioritize our ideas. It also encourages us to learn more and to resolve problems logically and sequentially. From this study, it was found that the logical problem-solving process consists of 5 steps: Focus the Problem, Describe the Physics, Plan the Solution, Execute the Plan, Evaluate the Answer. These processes will encourage learners to develop innovative and computational thinking skills, both of which are essential for life and work at the present time. Moreover, computational thinking is a sequential thinking skill allowing users to solve problems systematically, and is consistent with problem-based learning. Problem-based learning is aimed at assisting students to set their own learning goals through the consideration of a specific problem. Students will explore their own learning methods and report their learning process together with their conclusions and recommendations. Problem-based learning is not only used to solve problems. It is also used to enhance students' understanding and create new knowledge through questions encountered during learning, which in turn promotes efficient computational thinking. They can also use their imagination to look at the problem with the use of abstract thinking. This will let them see a way to solve the problem step-by-step and develop a sequential way of thinking. This process is not just about computer programming, because programming languages are constantly changing. Rather, the more important purpose is to teach students to think and connect problems until they can solve them systematically. From this research, learning Imagineering by solving logical problems consists of 6 important steps: 1) Problem Imagination stage, 2) Problem-solving Design stage, 3) Innovation Development stage, 4) Innovation Presentation stage, 5) Innovation Improvement stage, 6) Evaluation stage. Such learning also results in the development and encouragement of innovative skills on the part of learners. The process of Imagineering focuses on inspiration to realize the imagination of things that do not yet exist, then proceed to create the innovation by using the problem-based learning process where they can engage in thinking to solve specific problems. It focuses on practicing logical thinking in terms of prioritizing and reasoning. It also contributes to develop students' structured and systematic learning through practice, and through the development of the ability to seek knowledge and develop problem-solving abilities. This is consistent with Techakosit's research (Techakosit \& Nilsook, 2018). Logical solutions help learners analyze problems and find answers with the help of scientific logical thinking. It helps individuals to understand complex problems which is 
consistent with the research of Gao et al.

\section{Conclusion}

Imagineering learning method enhances the development of novel innovation through problem-based learning. The learning process is achieved through logical thinking which involves reasoning and decision making. The process starts from exploring and developing potential innovation for the assigned problems, setting up the goals of the innovation, and improving the results of the innovation to the creation of the innovation itself.

\section{Acknowledgments}

Thanks to the experts for your support, consultations and assistance, including advising on the research process. Thanks also to the King Mongkut's University of Technology North Bangkok (KMUTNB).

\section{References}

Angevine, C. (2017). Advancing Computational Thinking Across K-12 Education. Retrieved from https://digitalpromise.org/2017/12/06/advancing-computational-thinking-across-k-12-education/

Arends, R. J. (2001). Learning to Teach (5th ed.). McGraw-Hill.

Balim, A. G., Inel-Ekici, D., \& Ozcan, E. (2016). Concept Cartoons Supported Problem Based Learning Method in Middle School Science Classrooms. Journal of Education and Learning, 5(2), 272. https://doi.org/10.5539/jel.v5n2p272

Barkley, E. F., Major, C. H., \& Cross, K. P. (2004). Collaborative Learning Techniques: A Handbook for College Faculty. Wiley Imprint.

Bower, M., Wood, L. N., Lai, J. W. M., Howe, C., \& Lister, R. (2017). Improving the Computational Thinking Pedagogical Capabilities of School Teachers. Australian Journal of Teacher Education, 42(3), 54-56. https://doi.org/10.14221/ajte.2017v42n3.4

Chatwattana, P., \& Nilsook, P. (2017). A web-based learning system using project-based learning and Imagineering. International Journal of Emerging Technologies in Learning, 12(5), 4-22. https://doi.org/10.3991/ijet.v12i05.6344

Ching, Y.-H., Hsu, Y.-C., \& Baldwin, S. (2018). Developing Computational Thinking with Educational Technologies for Young Learners. TechTrends, 62(6), 563-573. https://doi.org/10.1007/s11528-018-0292-7

Cho, Y., \& Lee, Y. (2017). Possibility of improving computational thinking through activity-based learning strategy for young children. Journal of Theoretical and Applied Information Technology, 95(18), 4385-4393.

Choden, T., \& Kijkuakul, S. (2020). Blending Problem Based Learning with Scientific Argumentation to Enhance Students' Understanding of Basic Genetics. International Journal of Instruction, 13(1), 445-462. https://doi.org/10.29333/iji.2020.13129a

D’Uva, N. (2014). Walt Disney Imagineering. Retrieved from https://prezi.com/va6wlmn3-xe_/walt-disney-imagineering

Denning, P. J. (2009). The profession of IT Beyond computational thinking. Communications of the ACM, 52(6), 28-30. https://doi.org/10.1145/1516046.1516054

Disney, W. (1996). Walt Disney Imagineering: A Behind the Dreams Look at Making the Magic Real (1st ed.). Disney Editions.

Fogarty, R. J. (1997). Problem-based Learning and Other Curriculum Models for the Multiple Intelligences Classroom. Corwin (June 1, 1997).

Gagné, R. M., \& Briggs, L. J. (1974). Principthles of Instructional Design. Ted Buchholz. Retrieved from https://www.hcs64.com/files/Principles of instructional design.pdf

Good, C. V. (1973). Dictionary of Education (p. 518). McGraw Hill.

Greenwald, N. L. (2000). Learning form Problems. The Science Teacher, 67, 28-32.

Guzdial, M., \& Tew, A. E. (2006). Imagineering inauthentic legitimate peripheral participation. Proceedings of the 2006 International Workshop on Computing Education Research - ICER'06, 51. https://doi.org/10.1145/1151588.1151597

Heller, K., \& Heller, P. (2000). The competent problem solver for introductory physics. Greyden Press. 
Herrick, P. (1999). The Many Worlds of Logic (signed ed.). Harcourt College Pub (July 1, 1999).

Howard, B. S., \& Robyn, T. M. (1980). Problem-based Learning an Approach to Medical Education. Springer Publishing Company.

Hung, W., Jonassen, D. H., \& Liu, R. (2008). Handbook of Research on Educational Communications and Technology (D. Jonassen, M. J. Spector, M. Driscoll, M. D. Merrill, J. van Merrienboer, \& M. P. Driscoll Eds.). Routledge. https://doi.org/10.4324/9780203880869

Jarvis, P., \& Howard E. (2010). Getting Serious Play: Life Span Career Education. Education Canada, 46(3), $46-48$.

Jirasatjanukul, K., Yamjaroenki, M., \& Nilsook, P. (2016). A comparison between Systems Learning and Imagineering Learning of Computer Program undergraduate students from 3 different faculties at Phetchaburi Rajabhat University. Journal of Thai Interdisciplinary Research, 11(1), 15.

Kawamoto, K., \& Arai, N. H. (2008). Evaluation of Logical Thinking Ability through Contributions in a Learning Community BT - Large-Scale Knowledge Resources. In T. Tokunaga \& A. Ortega (Eds.), Construction and Application (pp. 326-333). Springer Berlin Heidelberg. https://doi.org/10.1007/978-3-540-78159-2_29

Kelley, D. (1990). Art of Reasoning with Symbolic Logic (expanded ed.). W.W. Norton.

King Mongkut's University of Technology Thonburi. (2010). Imagineering Project.

Kuiper, G., \& Smit, B. (2014). Imagineering: Innovation in the experience economy. CABI, September 14. https://doi.org/10.1079/9781780644653.0000

Lamprou, A., \& Repenning, A. (2018). Teaching how to teach computational thinking. Proceedings of the 23rd Annual ACM Conference on Innovation and Technology in Computer Science Education - ITiCSE 2018, 69-74. https://doi.org/10.1145/3197091.3197120

Langford, D. P. (2010). Imagineering. Tool Time for Education. Langford International, Inc.

Lockwood, J., \& Mooney, A. (2017). Computational Thinking in Education: Where does it Fit? A systematic literary review. International Journal of Computer Science Education in Schools, 2(1). https://doi.org/10.21585/ijcses.v2i1.26

Mario, R., Susan, L., \& Jerzy, R. (2012). Educational Technologies for Precollege Enginerring Education. IEEE Transactons on Learning Technologies, 5(1), 20-37. https://doi.org/10.1109/TLT.2011.16

McLoone, S. C., Lawlor, B. J., \& Meehan, A. R. (2016). The Implementation and Evaluation of a Project-Oriented Problem-Based Learning Module in a First Year Engineering Programme. The Implementation and Evaluation of a Project-Oriented Problem-Based Learning Module in a First Year Engineering Programme, 4(1), 71-80. https://doi.org/10.5278/ojs.jpblhe.v0i0.1243

Nilsook, P., \& Panita, W. (2013). Imagineering. Journal of Technical Education Development, 86(25), 33-37.

Obama, B. H. (2016). Computer Science for All. Retrieved from https://obamawhitehouse.archives.gov/blog/2016/01/30/computer-science-all

Development of characteristics in the new generation of learners to respond to the educational reformation in the 2nd decade by integrating IT in the project-based instructional management, (2012).

Poolsawas, B., \& Dokprakhon, P. (2016). Visual Programming and Computational Thinking Game. Journal of Information Science and Technology, 6(2), 9-16.

Pornsawan, I., \& Charan, S. (2012). Designing of Adaptive Coaching System to Enhance the Logical Thinking Model in Problem-based Learning. Procedia - Social and Behavioral Sciences, 46, 5265-5269. https://doi.org/10.1016/j.sbspro.2012.06.419

Qiyue, F. (2013). Imagineering. Business Innovation from the Experience Perspective. Retrieved from $\mathrm{http}: / /$ www.fongqiyue.com/Imagineering_FongQiyue.pdf

Ruthmann, A., Heines, J. M., Greher, G. R., Laidler, P., \& Saulters, C. (2010). Teaching computational thinking through musical live coding in scratch. Proceedings of the 41st ACM Technical Symposium on Computer Science Education-SIGCSE'10, 351. https://doi.org/10.1145/1734263.1734384

Saenyakun, A. (2010). A Develop Computer-Based Logical Thinking Learning Model. King Mongkut's University of Technology North Bangkok. 
Schultz, N., \& Christensen, H. P. (2004). Seven-step problem-based learning in an interaction design course. $\begin{array}{llll}\text { European Journal of Engineering } & \text { Education, }\end{array}$ https://doi.org/10.1080/03043790410001716248

Solso, R. L. (1998). Cognitive Psychology. Boston Allyn and Bacon.

Spencer, J. A., \& Jordan, R. K. (1999). Learner centred approaches in medical education. BMJ, 318(7193), 1280-1283. https://doi.org/10.1136/bmj.318.7193.1280

Suebnukarn, S., \& Haddawy, P. (2004). A collaborative intelligent tutoring system for medical problem-based learning. Proceedings of the 9th International Conference on Intelligent User Interface - IUI'04, 14. https://doi.org/10.1145/964442.964447

Techakosit, S. (2016). The learning process of scientific imagineering through AR in order to enhance STEM literacy. International Journal of Emerging Technologies in Learning (IJET), 11(07), 57-63. https://doi.org/10.3991/ijet.v11i07.5357

Techakosit, S., \& Nilsook, P. (2018). The development of STEM literacy using the learning process of scientific imagineering through AR. International Journal of Emerging Technologies in Learning, 13(1), 230-238. https://doi.org/10.3991/ijet.v13i01.7664

Threekunprapa, A., \& Yasri, P. (2020). Unplugged Coding Using Flowblocks for Promoting Computational Thinking and Programming among Secondary School Students. International Journal of Instruction, 13(3), 207-222. https://doi.org/10.29333/iji.2020.13314a

Wee, K. N. L. (2003). Authentic Problem-Based Learning. Prentice Hall (November 2003).

Wing, J. M. (2006). Computational thinking. Communications of the ACM, 49(3), 33-35. https://doi.org/10.1145/1118178.1118215

Woods, L. (2017). 6 Approaches to Problem Solving-How Does Your Mind Work? Retrieved from http://www.managingamericans.com/BlogFeed/Professional-Development/6-Approaches-to-Problem-Solvi ng-How-Does-Your-Mind-Work.htm

\section{Copyrights}

Copyright for this article is retained by the author, with first publication rights granted to the journal.

This is an open-access article distributed under the terms and conditions of the Creative Commons Attribution license (http://creativecommons.org/licenses/by/4.0/). 